\title{
NO ES MADERA PARA VASALLOS, SINO DEL REY LAS POLÍTICAS FORESTALES DE LOS HABSBURGO EN PORTUGAL (1609-1640)
}

\author{
Koldo Trápaga Monchet \\ Universidad Rey Juan Carlos
}

\begin{abstract}
RESUMEN. En este trabajo se abordan ciertos aspectos de las políticas forestales puestas en marcha por Felipe III y Felipe IV en Portugal en relación con la construcción de las armadas reales. En primer lugar, se estudian algunas de las disposiciones legislativas aprobadas en las décadas de 1590 y 1600, porque permiten comprender luego las posteriores políticas de búsqueda e incorporación de las masas forestales al patrimonio real mediante la figura de coutar, ya entre las décadas de 1610 y 1630 . En segundo lugar, se muestran algunos procesos contrarios de desmantelamiento y desvinculación de la gestión real de ciertas áreas forestales a manos de los oficiales reales. Y, por último, se analizan los mecanismos de administración directa empleados por la monarquía, tanto a través de los oficiales reales como de las comisiones extraordinarias, para la provisión de maderas con destino a la construcción de sus armadas.
\end{abstract}

Palabras clave: bosques reales, políticas forestales, Portugal, armadas, Habsburgo

\begin{abstract}
This article aims at shedding light upon some elements of the state forestry policies implemented in the realm of Portugal during the kingships of Philip III and Philip IV, in regard with the shipbuilding activity for the royal fleets. Firstly, it intends to know some of the laws issued during the $1590 \mathrm{~s}$ and $1600 \mathrm{~s}$, as they were the ground for the subsequent state forestry policies implemented by the Crown during the decades 1610 to 1630 by the so-called mechanisms of coutar. Secondly, the article explores processes of shrinking the royal forests and taking the administration away from the royal ministers. Furthermore, this article also focuses on the mechanisms run by the Crown to ensure the timber supply for shipbuilding either conducted by the royal officials or extraordinary appointments.
\end{abstract}

Keywords: royal woodlands, state forestry, Portugal, royal fleets, Habsburg

Recibido: 26-3-2019 • Aceptado: 18-9-2019 • koldo.trapaga@urjc.es 
Si EN LA ACTUALIDAD vivimos en la denominada «edad de plástico», que implica que nuestra sociedad es prácticamente indisociable de este producto, la época moderna ha sido considerada la «edad de la madera»; un género que abarcaba todos los aspectos de la cultura material, desde la construcción hasta la obtención de combustible, o de materia prima para la fabricación naval, algo que llevó al establecimiento de una severa legislación cuyo fin era regular el acceso y uso de la misma (Perlin, 2005; Williams, 2006, pp. 127-225). En este sentido, es bien conocida la carta de Felipe II sobre la conservación de montes y bosques del reino de Castilla (Kamen, 1998, p. 192). Durante su reinado fue cuando se estableció la Superintendencia de Montes y Bosques con el objetivo de reglamentar administrativamente la explotación y gestión de los mismos (Martínez González, 2015; Wing, 2015). El soberano, más que procurar esa explotación a corto plazo, pretendía establecer una organización administrativa que permitiese asegurar la existencia de bosques fácilmente accesibles al objeto de garantizar la actividad naval a las generaciones futuras. Así, bosques y barcos eran dos caras de una misma moneda, y esto no fue un fenómeno exclusivo de la Monarquía Hispana, sino, más bien, un proceso común a todas las potencias marítimas europeas de la época (Albion 1928; Appuhn 2000; Bamford 1956; Falkowski 2017; Lane 1975; Radkau 2008; Warde, 2006, pp. 32-48).

En este trabajo se aborda, en primer lugar, el estudio de las disposiciones normativas forestales dadas en Portugal, ya que nos permiten comprender la política forestal puesta en marcha por la corona española en ese reino a la hora de incorporar y de crear nuevos bosques gestionados por oficiales reales. Como se ha indicado, estos bosques estaban pensados para proveer de madera a sus armadas y su incorporación, temporal o definitiva, al patrimonio real fue realizada mediante la figura de coutar, aspecto este que nos detendremos a estudiar en el segundo apartado. Allí, veremos también el proceso contrario, es decir, el desmantelamiento de las reservas forestales sometidas a control real, para finalizar nuestra investigación prestando atención a las diferentes modalidades y fórmulas empleadas entre 1609 y 1640 por la administración portuguesa para garantizar la provisión de maderas a los astilleros de Lisboa.

\section{La regulación y protección de las masas forestales reales y privadas: «no es madera para vasallos»}

«E o sustento deste Reino são as conquistas, era pera lhe durar é forçado que durem delas o que se não podera conseguir sem muito cuidado e vigilancias nas madeiras» ${ }^{1}$. Éste fragmento resume la estrecha relación existente entre los bosques

Arquivo Histórico Ultramarino (en adelante AHU), Conselho Ultramarino (en adelante CU), Reino, caja 5a, carpeta 20 . 
y las armadas reales. Pertenece a una carta redactada en 1626 por el monteiro-mor [guarda mayor], don Francisco de $\mathrm{Melo}^{2}$, quien pretendía denunciar así la falta de responsabilidad del tribunal de la Mesa del Desembargador do Paço, por haber dado licencia a Vicente Freire para cortar entre 50 y 60 árboles en sus tierras sin tomar en consideración los apuros que la corona tenía para satisfacer la demanda de maderas para sus armadas. En ella, a continuación, el monteiro-mor criticaba ampliamente la gestión del transporte de las maderas realizada durante los últimos cinco años, por haber causado, en su opinión, la pérdida de varios miles de árboles ${ }^{3}$. En enero de 1623, sabemos que otro particular, Antão Vas de Freire, había obtenido una licencia para talar 150 árboles en sus posesiones, situadas en la villa de Samora, tras haber sido inspeccionadas conjuntamente por el mencionado monteiro-mor y Agostinho de Aguiar Figuereido ${ }^{4}$. De este modo, con estos ejemplos, pretendemos mostrar al lector que la corona sí disponía de un marco jurídico que le permitía regular el uso de los bosques de los particulares, al ser considerados un elemento estratégico para la fábrica de las armadas y, en consecuencia, para el bien de los reinos.

Las actuaciones del mencionado monteiro-mor y de otros oficiales reales se fundamentaban en la figura jurídica de coutar. Conforme al Diccionario de Lengua Portuguesa compuesto por Rafael Bluteau, «coutar» signficaba otorgar el privilegio de couto a un señor sobre un territorio; un territorio, al cual los jueces reales no podían acceder. De hecho, los coutos tenían sus propios funcionarios y fuero privativo (Bluteau, 1799, vol. 1, p. 344). Como se expondrá más adelante, todo apunta a que coutar era dar la gestión de esos territorios, que hasta entonces habían sido de particulares o de corporaciones, a oficiales de la corona con jurisdicción propia. Aunque no podemos asegurar con exactitud cuándo la monarquía portuguesa comenzó a acudir a esta práctica, se considera que la incorporación del reino de Portugal a la Monarquía Hispana supuso para el primero una modernización administrativa, que afectó también a la gestión de las masas forestales (Hespanha, 1989, pp. 50-73). Este proceso de modernización se habría iniciado a raíz de la notable recopilación de la legislación forestal publicada en 15845. En ella, Felipe II vinculó aún más, al menos en el plano legal, la gestión forestal a las necesidades militares de la marina portuguesa. Así, en 1594 ordenaba «descoutar» [desmantelar] los bosques reales reservados a las actividades cinegéticas $^{6}$ (Devy-Vareta, 1986, pp. 33-34; Labrador Arroyo, 2009, p. 227). En 1597

Servía como monteiro-mor desde 1612, (Neves, 1965, p. 49; Labrador Arroyo, 2009, p. 238).

AHU, CU, Reino, 5a/20.

AHU, CU, Reino, 4/8. Desafortunadamente carecemos de información biográfica de la mayoría de los personajes citados a lo largo del trabajo.

Biblioteca de Ajuda (en adelante B.A.), Manuscritos, 44-XIII-61.

Biblioteca e Arquivo Histórico Ministerio Obras Púbricas (en adelante BAHMOP), Montaría-mor do reino (en adelante MMR), núcleo 9. 
disponía en cambio, y en consideración a la importancia de su servicio «e bem d'estes meus Reinos», acrecentar el pinar de Leiria, porque sus árboles proveían de madera a la armada (Arala Pinto, 1938, vol. 1, pp. 159-162; Costa, 1997, pp. 319-320). Al año siguiente, el monarca puso en vigor una ley por la que los árboles de los vasallos o particulares - tanto de individuos como de corporaciones - podrían llegar a ser gestionados como si fuesen bosques reales. La misma disposición aparecerá repetida luego en el reglamento del monteiro-mor de 1605, donde se especifica nuevamente que, llegado el caso, las tierras de los particulares podían ser administradas como si perteneciesen a la corona (Andrade e Silva, 1854, vol. III, p. 109). La ley distinguía claramente entre bosques reales y aquellos que, tras un minucioso proceso de recogida de información realizado en años previos, eran privados, pero cuya gestión el soberano entregaba a los oficiales reales mediante esta fórmula: «estas são as matas dos particulares, que fican dentro nesta Montaria, e quero se guardem como minhas proprias» (Andrade e Silva, 1854, vol. III, pp. 112-124). Es decir, otorgaba a estos bosques una consideración administrativa que permitía su control directo por la monarquía a través de la acción de «coutar», una práctica forestal que continuó usándose en los siguientes decenios.

En 1617-1618, la Monarquía Católica se implicó en la Guerra de los Treinta Años y en 1621 finalizaba la Tregua de los Doce Años, dando inicio así a un periodo de numerosos e intensos enfrentamientos bélicos con Holanda. La monarquía puso en marcha entonces un ambicioso programa de construcción naval que incluía al reino de Portugal (Thompson 1976, pp. 198-200; Gaillard, 1982, pp. 255-298; Dadson, 1991, pp. 29-60). Las décadas de 1620 y 1630 fueron las de mayores choques armados con la república holandesa, sea en Brasil o sea en Asia, y no sería hasta el decenio de 1630 que los portugueses no se vieron sobrepasados por los holandeses en ambos frentes (Boyajian, 1993, pp. 188-199, 202-213; Murteira, 2011, pp. 179-190 y 2012, pp. 287-89).

Fueron años en los que la legislación forestal conoció un auge extraordinario. Por ejemplo, una disposición real de 1618 ordenaba replantar alcornoques y pinos en todas las comarcas de Portugal, la cual sería repetida en 1633 arguyéndose que aún no había sido plenamente ejecutada (Devy-Vareta y Alves, 2007, p. 66). En la misma línea, en 1620 se remitió una orden al corregidor de la comarca de la villa de Tomar, poniendo especial énfasis en su aplicación también en el término de la villa de Abrantes, a la vez que se le recordaba la prohibición de cortar alcornoques, robles y encinas, y de hacer carbón vegetal en un área de 10 leguas alrededor del Tajo, ya que estas especies eran cruciales «para as armadas destes meus Reino, e porque sou informado que contra a dita prohibição se cortão, e escascao muitos arvores» ${ }^{7}$. En 1622, Felipe IV enviaba a

AHU, CU, Reino, 3/34. 
Lisboa el nuevo reglamento [tombo] que se había aprobado para los pinares de Leiria y los coutos de Alcobaça ${ }^{8}$, y que el Conselho da Fazenda afirmaba no haber llegado a recibir ${ }^{9}$. En agosto de 1623, el soberano le mandaba el tombo donde se detallaba el procedimiento para el corte de maderas en Ribatejo ${ }^{10}$. Un año más tarde, en 1624, los gobernadores de Portugal ordenaban al monteiro-mor realizar una recopilación de las infracciones cometidas a ambas orillas del río Tajo — extracción de corteza, cortes parciales de madera, fuegos ${ }^{11}$ - . Asimismo, hubo incluso un intento de elaborar un nuevo tombo para el pinar de Leiria, que en 1626 se remitiría al gobernador de Portugal para ser ejecutado por medio de la Junta dos Povos ${ }^{12}$.

Todas estas disposiciones contribuyeron a extender la superficie de los bosques reales — entre las que cabe destacar el reglamento del monteiro-mor de 1605-, pero su aplicación requería de un personal numeroso que garantizase la salvaguarda y gestión efectiva de la misma (Labrador Arroyo, 2009, pp. 238-241; Trápaga Monchet, 2017, pp. 18-20). Sin embargo, y a pesar de la considerable extensión que llegaron a tener los bosques reales en Portugal, la Monarquía Católica no dejó nunca de encontrar e incorporar al patrimonio regio nuevas masas arbóreas que estuviesen cerca del mar o próximas a los afluentes fluviales (ejemplos similares en Wing, 2012, p. 129-136; Appuhn, 2000, pp. 877-881). De este modo, se garantizaba el transporte rápido y económico de la madera hasta Lisboa, y en este proceso la incorporación de las tierras de los particulares al patrimonio regio se produjo mediante la ya mencionada figura de coutar.

\section{La creación y el desmantelamiento de los bosques reales}

A finales del reinado de Felipe II, en 1598, don Pedro Castilho, obispo de Leiria y presidente del Desembargo do Paço, recomendó al soberano la creación de pinares en áreas próximas al monasterio de Alcobaça, contiguo al antiguo pinar de Leiria ${ }^{13}$ (Mapa 2). Felipe II aceptó la propuesta y procedió a coutar las áreas sugeridas por don Pedro Castillho. Años más tarde, en 1608, el obispo don Jorge de Ataide, en su calidad de abad del mencionado monasterio de Alcobaça, escribía que tras realizar averiguaciones en las comarcas de Pederneira, Pataias y en lugares cercanos a la abadía, sus

AHU, CU, Reino, 3/90.

AHU, CU, Consultas do Serviço Real (en adelante Consultas), cod. 35, f. 236r.

AHU, CU, Reino, 4a/49 y Consultas, cod. 35, f. 236r.

BAHMOP, MMR, núcleo 8.

Archivo General de Simancas (en adelante AGS), Secretarías Provinciales (en adelante SSP), lib. 1520, f. $125 \mathrm{r}-\mathrm{v}$.

13 Don Pedro fue virrey de Portugal y dirigió la diócesis de Leiria desde 1583 hasta 1607, por lo que conocía perfectamente el territorio. Su buena relación con el soberano Felipe II, puede explicar su interés o colaboración en la creación de los pinares, (Labrador Arroyo, 2018, vol. 12, pp. 405-406). 
habitantes se quejaban de las extorsiones cometidas por Jorge da Silva, guarda-mor del pinar de Leiria ${ }^{14}$ (Costa, 1997, pp. 319-320). Esto significa que la coutada decretada en su día por Felipe II había originado a los labradores la pérdida de colmenas, viñas y otras propiedades, impidiéndoles además sustentar el ganado, poniendo de este modo en riesgo su bienestar material y su supervivencia.

A la vista de estos informes, en mayo de 1610, el Conselho da Fazenda apuntaba que no se había conseguido crear el nuevo pinar, por lo que proponía al monarca descoutar $^{15}$. Tres años más tarde, en 1613, una parte del pinar existente ardió. Las investigaciones sobre este suceso, conducidas por Manuel Veloso Cabral, juez de la ciudad de Leiria, demostraron que se trató de un incendio provocado, con epicentro en la coutada del citado pinar, muy probablemente en la zona creada durante el reinado de Felipe $\mathrm{II}^{16}$. Los incendios fueron de tal magnitud que durante los siguientes años los bosques reales de Leiria no pudieron satisfacer la demanda de madera de las armadas reales. Por ello, desde 1621, la mayor parte de esta se extraía de los bosques de particulares situados en Batalha, «por ser muito bons e em grande quantidade» (Mapa 2). Estos bosques no sólo ofrecieron maderamen para los barcos construidos en Pederneira, São Martinho y Peniche, sino que también para otros lugares del reino.

A pesar de esta intensa producción forestal y de los incendios provocados por los vecinos para el cultivo de «olivas e terras de pão», a finales de la década de 1620 la monarquía seguía disponiendo de bosques fácilmente accesibles para sus armadas. En ese sentido, y con la intención de salvaguardar sus propios intereses, el rey había ordenado al guarda mayor del pinar de Leiria que no permitiese realizar cortes en ellos sin la obtención de una licencia previa, limitando así el acceso y uso de los mismos a los habitantes locales. Quizás esto explique que en 1630 se desatase un gran incendio en la zona con origen en las tierras de los particulares, cuya extinción resultó muy complicada. De ahí que la corona abriese luego una investigación para aclarar cuáles eran los bosques útiles a sus armadas, con vistas a protegerlos y evitar incendios semejantes ${ }^{17}$.

En 1615, el monteiro-mor informaba a las autoridades lisboetas que las extracciones madereras realizadas en los últimos años habían sido excesivas, a lo que se añadía el recurrente problema de los incendios, cortes parciales de árboles y extracción de las cortezas. Para dar un respiro a los bosques reales que realmente habían abastecido a las armadas, este oficial real proponía coutar nuevas áreas forestales que asegurasen la provisión de maderamen. En este sentido, apuntaba que en la zona comprendida entre

\footnotetext{
14 Don Jorge de Ataide fue un personaje de excepcional importancia en el reino de Portugal (véase, Labrador Arroyo, 2018, vol. 6, p. 22-24).

15 AHU, CU, Reino, 1/62.

16 AHU, CU, Reino, 1a/19.

17 AHU, CU, Consultas, cod. 476, f. 151.
} 
Santiago de Caçem y el Algarve había grandes extensiones de alcornoques, tanto de particulares como de los municipios, con buena madera para las armadas (Mapa 1). En consecuencia, proponía al soberano coutar los bosques para evitar «sentir falta em cousa tão importante pera estos seus reinos» ${ }^{18}$.

La corona demandó más información, por lo que en varias ocasiones exigiría al Conselho da Fazenda que enviase un experto a reconocer estos territorios in situ ${ }^{19}$ (Magalhães, 1970, pp. 190-192). En 1618, el gobernador del Algarve aseguraba que existían multitud de maderas que permitirían la construcción de toda suerte de embarcaciones, incluyendo naos de India y navíos para las armadas ${ }^{20}$. Por su parte, el monarca demandó al mencionado Conselho da Fazenda un informe más pormenorizado, con lo que este se decidió por fin a enviar a dos expertos a reconocer la zona, quienes informaron acerca de la existencia de dos áreas geográficas que cumplían con las premisas de calidad, cantidad y transporte fácil y económico de la madera hasta Lisboa ${ }^{21}$.

La primera de estas áreas comenzaba en la villa de Odemira, donde los citados expertos encontraron maderas de alcornoque y roble apropiadas para la fábrica de cualquier tipo de embarcación (Mapa 1). En el valle identificado como «Estassa», situado en Reguengo Grande y Pequenho, había también maderas, a una distancia de entre una y dos leguas del río Odemira. En el valle de los «Bassiaes» había mucha a una legua o legua y media del río Mira, la cual pertenecía a Antonio Martines, del que nada sabemos. En el valle de «Deuiza», el doctor Jerónimo Vieira, residente en Lisboa, disponía a su vez de «mui boa madeira», con facilidad para ser embarcada hacia la capital del reino. Todos estos lugares estaban próximos al mencionado río Odemira, lo que permitía conducir el maderamen hasta el puerto de Vila Nova de Milfontes, donde serían apilado para su acarreo a Lisboa.

La segunda área visitada comenzaba en el camino de Odemira hacia Monchique (Mapa 1). En la Ribeira da Perna da Negra los expertos informaban de la existencia «muita madeira e mui boa». El problema eran las condiciones geográficas que obligarían a transportarla hasta las vías fluviales con bueyes en lugar de carros. El maderamen

AHU, CU, Reino, 1a/50.

En 1618, lo hizo en tres ocasiones, AHU, CU, Reino, 2/53.

Los mapas de este trabajo han sido desarrollados a partir del software Google Earth Pro. La georeferenciación se ha realizado por medio del Centro de Informação Geoespacio do Exército de Portugal (http://www.igeoe.pt/igeoesig/), y la búsqueda toponímica a través del mismo y Googlemaps (http://scrif.igeo.pt/asp/toponim.asp; https://www.google.com/maps). Asimismo, hacer constar que la localización geográfica señala en los mapas es aproximada, es decir, no necesariamente coincide con total precisión con los lugares indicados en la documentación archivística. Lamentablemente, esta no aporta suficiente información para geo-referenciar con total exactitud, aunque sí, insistimos, de un manera que estimamos bastante aproximada, los lugares de extracción de las maderas o aquellos dónde estuvieron trabajando los comisionados. Acerca de las posibilidades del SIG aplicado a la historia, véase Crespo Solana 2013, y Owens 2007.

21 Las siguientes líneas se fundamentan en AHU, CU, Reino, 38/10. 
Mapa 1. Exploraciones territoriales en 1618

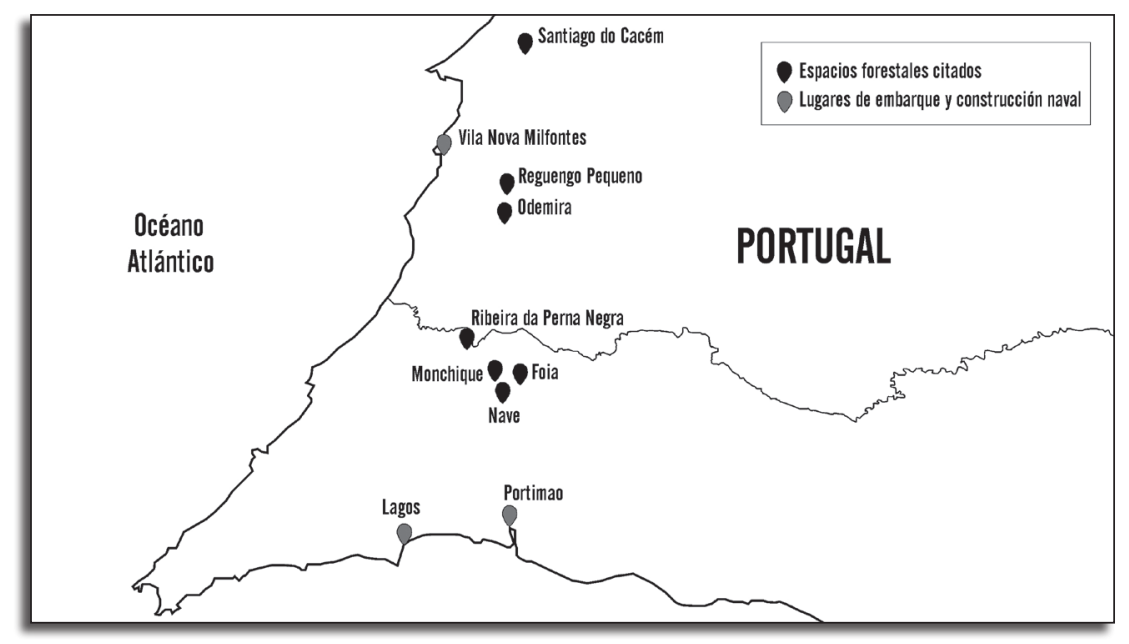

se conduciría luego por el río hasta Vila Nova de Portimão, el actual Portimão. En Monchique había dos zonas interesantes: Foya [¿Fóia?] y Nave, y desde aquí hacia el sur, camino del mar, los ministros del rey procedieron a reconocer multitud de bosques localizados a unas tres leguas de Portimão, para cuyo transporte o se utilizarían carros.

En 1617, Jorge de Araujo Estacos fue comisionado para inspeccionar el pinar de la villa de Cabeção y aledaños, e investigar los cortes que allí se habían realizado sin permiso de la corona (Mapa 3). El comisionado estimaba que en los dos últimos meses se habían talado unos cincuenta pinos y que los mayores infractores eran el padre fray Francisco Domingo, prior de aquella villa, y dos zapateros de la misma. El citado Jorge de Araujo había sido facultado por el Conselho da Fazenda para realizar un nuevo reglamento destinado al buen cuidado de la «mata e pinhal», pero-indicaba que antes de hacerlo debía saber primero si el monarca iba a disponer solo la conservación del pinar o también la de las tierras colindantes, pues sus dueños no estaban dispuestos a venderlas, por lo que la única solución era que el monarca las declarase como un bien público bajo la excusa de «criar madeiras» para la construcción naval. De hacerlo así, el juez podría entonces tasar las tierras de los particulares y proceder a su compra para la corona a un precio justo ${ }^{22}$. El nacimiento de este pinar exigía crear 200 alqueires $^{23}$ de pinos, mientras que para su protección se proponía nombrar un guarda mayor y

23 Alqueire: «terra lavrada para se penetrar das aguas, e deixada em descanço por hum anno, ou mais», (Bluteau, 1799, vol. 1, p. 65).
} 
dos menores. El primero de ellos debería ser un «home muito poderoso, aposentado de que todos temem». Por su parte, sabemos que João Martines y Francisco Coelho fueron propuestos para guardas menores ${ }^{24}$. Hecho esto, Jorge de Araujo ordenó se diese un pregón en la plaza y demás lugares «públicos» de la villa, haciendo saber que todos los que tuviesen tierras en propiedad o arrendadas en el pinar o en los territorios colindantes estaban obligados a mostrar los títulos de compra y arrendamiento. Con esta información, Araujo elaboró una relación de los títulos de compra, indicando el nombre de los dueños de los predios, las dimensiones de los mismos, su ubicación y el nombre de quienes se las habían vendido. Asimismo, hizo recomendaciones sobre cómo se podría crear, conservar y aumentar el pretendido pinar. En el párrafo introductorio de las mismas daba las razones de su creación:

Avendo Sua Majestade que a madeira de Cabeção é de importancia para suas naos, sen embargo do muito custo que o carreto dela faz, convêm grandemente guardarse e acrecentarse aquele pinhal, porque na forma em que esta é muito pequeño, e isto se podera fazer pela maneira seguente.

Además de ello, anticipaba que el rey compraría las tierras del pinar y áreas circundantes mediante el desembolso aproximado de 900.000 reis. Posteriormente, éste debía ser delimitado «en redondo pelas balisas e confrontações», dando vida de este modo a un espacio de más de una legua de largo - 6 kilómetros - , el doble que el actual (Cortesão, 1993, p. 70-71). Este espacio debía dividirse en cuatro segmentos — «folhas»— para que se «lavrem» cada cuatro años, con lo que los pinos tendrían tiempo suficiente para crecer. Esas «folhas» o segmentos podrían arrendarse y con el dinero obtenido se abonarían los sueldos de los guardas. Lo más importante era limpiar el pinar anualmente, tarea que podía ser realizada por el pueblo, cuyos habitantes quedarían exentos del pago del quinto de recoger frutos, a causa de su pobreza ${ }^{25}$.

Ya en la década de 1620 cabría señalar, entre otras actuaciones, la del doctor Agostinho da Cunha Vilas Boas, comisionado por la corona para delimitar «chãos» en Almeirim, los cuales posteriormente serían convertidos en coutadas $^{26}$ (Mapa 3). En este sentido, en 1624, Antonio Rodrigues da Costa informaba a petición de la corona, de que en una zona del pinar dos Medos había varios matos de pino que, al parecer, carecían de dueño y que en unos diez años estarían en su punto óptimo para la realización de feitorías, es decir, para la provisión de madera con destino a la industria naval ${ }^{27}$.

No disponemos de datos de estos dos individuos, pero es de creer que residían cerca del pinar.

AHU, CU, Reino, 2/16.

AHU, Consultas, cod. 37, f. 111v.

AHU, CU, Reino, 4a/9. 
Sin embargo, en ocasiones, se dio el proceso contrario, de descoutar los bosques reales y confiar su gestión a otras personas. Por ejemplo, en 1618 el monteiro-mor del reino recomendaba enviar un desembargador do Paço al área de Ribatejo, porque los bosques reales y de los particulares eran escasos y habían sido muy sobreexplotados durante los últimos años. Ante esto, el monarca ordenó proteger los bosques de los mencionados particulares como si fuesen suyos ${ }^{28}$. Por su parte, los habitantes de la zona habían propuesto a la corona convertir las tierras en sesmarias. Éste era un contrato merced al que se daba la tierra a un particular a cambio del cumplimiento de ciertas obligaciones, una de las cuales solía ser el cuidado de los árboles para la construcción naval ${ }^{29}$ (Cabral y Cesco, 2008, pp. 60-61, y pp. 69-70). Varios oficiales reales, como el provedor dos armazéns, se opusieron a ello porque las maderas de estas tierras no eran buenas por tener cultivos cerca $^{30}$. Es más, el monteiro-mor las consideraba pobres, si bien indicaba que en las coutadas reales había machieiros [alcornoques jóvenes] que daban para construir unas cien naos, por lo que debían ser protegidos durante su crecimiento ${ }^{31}$.

A finales de la década de 1620 en el Conselho da Fazenda se debatió abiertamente la posibilidad de descoutar las tierras de la zona del Ribatejo. Esto implicaba que la corona ya no las gestionaría directamente, optándose entonces por disponer las tierras en régimen jurídico de sesmaria. En los años siguientes llegarían al Conselho da Fazenda noticias de que las masas arbóreas de pino y alcornoque estaban siendo destruidas por cortes e incendios. Es probable que éste negocio fuese objeto de más discusiones, sin embargo, nada sabemos de la zona de Ribatejo hasta 1639. A comienzos de este año, los miembros del citado Conselho da Fazenda calificaban una vez más la provisión de maderamen como de altísima importancia «ao serviço de Vossa Magestade, bem de Sua Fazenda e vasalos, pois sendo as madeiras tão necesarias para as fabricas das naos da India e os navios das conquistas, estão hoje acabadas, e de maneira gastadas que se trazem de maes de veinte legoas a embarcação $\rangle^{32}$. Por esta razón, Afonso Botelho, desembargador do Paço, fue elegido para investigar los cortes y quemas mencionados, pero al ser corregidor civil de Lisboa el Conselho optó por el también desembargador Ignacio Ferreira. Éste había estado encargado del cuidado y explotación de los pinares reales de Almeirim (Mapa 3). En su informe, avisaba de

28 AHU, CU, Reino, 2/70.

$29 \quad$ En el siglo XVIII esta figura jurídica fue utilizada por la corona en Brasil para apropiarse de tierras de particulares, arguyendo que los éstos no habían cumplido con su obligación de cuidar los bosques para la Marina.

30. Acerca de la figura del provedor dos armazéns, véase Costa, 1997, pp. 265-66.

31 AHU, CU, Reino, 2/70.

32 AHU, CU, Reino, 10/41. Las siguientes líneas se fundamentan en esta referencia. 
que en Muge «trazem sonegado a fazenda de Vossa Magestade hum pinhal de consideração», sin presentar los títulos de propiedad. En sendas cartas al Conselho de 12 y 17 de febrero de 1639, Ferreira indicaba que no había pinares a lo largo del Tajo, por lo que ofrecía plantar a su cargo 60 moios de pinhões con destino a los pinares reales en un plazo de tres años. El citado Conselho recomendaba aceptar la oferta, señalando a continuación a Ferreira los límites y espacios donde sembrar 20 moios anuales en los próximos tres años. Pero el negocio se torció, ya que Ferreira sería destinado a Oporto. Había pues que encontrar un sustituto que continuase evaluando los bosques de Ribatejo. El elegido fue el licenciado Manoel de Nobrega Vilas Boas, quien se hallaba desplazado en el área ejerciendo el oficio de conductor, como feitor, de maderas de alcornoque. En este sentido, el 7 de julio de 1639 escribía al provedor dos armazéns, Vasco Fernandes César, informándole de que tres grandes incendios estaban arrasando las coutadas reales, los que suponía que en adelante las maderas tendrían que buscarse a 10-12 leguas del Tajo, gastándose así una ingente cantidad de dinero en su transporte hasta las vías fluviales.

A causa de estos preocupantes informes, la corona comisionaría a Manoel da Nobrega para recabar de primera mano información sobre las áreas forestales del Ribatejo ${ }^{33}$. Éste comprobó, tanto en persona como a través de la información de numerosos testigos, que en las villas de Chamusca y Ulme el descoutamiento de las áreas forestales y su entrega en sesmarías había resultado desastroso para los intereses de la corona (Mapa 3). Tras retirarse el personal encargado de su protección, los habitantes de la zona habían aprovechado para cortar árboles por el pie y transformarlos en $a_{c h}$ s $^{34}$. De hecho, trataban los bosques como si fuesen «cousa propia», sin consideración de su verdadera transcendencia para el porvenir del reino. Así, uno de ellos había cortado en una ocasión hasta 150 alcornoques jóvenes por el pie. El principal daño procedía, en cambio, de que los hombres de mal vivir ya no tenían ninguna autoridad que pudiese frenarlos, por lo que «agora com desamparo das coutadas» habían aprovechado para realizar enormes fuegos para obtener $\operatorname{cinzas}^{35}$, bien a partir de los árboles reales o bien de los alcornocales de los particulares que la monarquía destinaba a la construcción de las armadas reales. Es más, los malhechores actuaban amparados por el ministro encargado de proteger estas masas forestales, quien otorgaba licencias de corte tan generosas que no sólo permitían a los «cinzeiros» quemar lo que quisiesen, sino también a sus propios criados. Como en esas licencias no se registraban los nombres de las personas autorizadas, aquellos que las obtenían las empleaban para incluir en ellas

Las siguientes líneas se fundamentan en AHU, CU, Reino, 10/40.

Achas: «lasca de lenha», (Bluteau, 1799, vol. 1, p. 17).

Cinzas: «o que resta do corpo de combustible bem queimado», (Bluteau, 1799, vol. 1, p. 274). 
a quienes consideraban oportuno. Además, en caso de detenerse a los culpables, había en ellas una clausula expresa por la que sus titulares podían ser liberados aun en el caso de demostrarse su culpabilidad. Esto explica que de la localidad de Chamusca partiesen todas las semanas a Lisboa dos barcos de cinzas de alcornoque de unos 30 moios, para cada uno de los cuales se quemaban unos mil árboles.

El comisionado de la corona, Manoel de Nobrega, indicaba que males tan grandes requerían de remedios proporcionados. En consonancia, ofertaba una batería de propuestas destinadas a revertir el retroceso y la desaparición de las masas forestales, como retirar todas las licencias que se diesen a los cinzeiros o que estas se entregasen a personas de «boa vida e confiança» registrando en ellas sus nombres, donde, además, se precisaría la cantidad necesaria de cinzas a extraer y su precio. Junto a ello, intentando revertir la situación, desde Lisboa se le concedieron poderes para proceder judicialmente contra los culpables de la quema de las maderas.

\section{El suministro de las maderas para las armadas reales: procedencia geográfica y agentes}

Durante la edad moderna hubo en la Monarquía Hispana un debate más o menos recurrente sobre si la corona debía administrar directamente la construcción de las armadas reales, o bien hacerlo a través de la vía del asiento (Sánchez Torres, 2013, pp. 159-199). Durante los reinados de Felipe III y Felipe IV, que es el periodo aquí estudiado, la monarquía apostó casi siempre por un sistema de contratación realizado bajo la fórmula del asiento, contrario por tanto al sistema de administración directa que mayoritariamente se había empleado entre 1589 y 1598 (Goodman, 1997, pp. 29-33; Philips, 1991, pp. 41-60; Thompson, 1976, pp. 192). No es objeto de este trabajo discutir acerca de la naturaleza pública o privada de la figura del asentista, sino acercarnos a las formas de provisión de madera empleadas por la corona para construcción y reparación naval en Lisboa (Martínez González, 2015b), y, junto a ello, hacer salir a la luz la «geografía de la madera» portuguesa a partir de la consideración de los lugares de extracción de la misma.

Respecto a este último punto, Fredéric Mauro, en su trabajo sobre Brasil, Portugal y el Atlántico realizaba en 1983 una aproximación a esa geografía para el imperio portugués (Mauro 1983, pp. 46-57, 129-135). Casi al mismo tiempo, Nicole-Devy Vareta geo-referenciaba los bosques reales, aunque sin especificar cuáles eran los que expedían maderamen a los astilleros de Lisboa (Devy-Vareta, 1985 y 1986). Por su parte, Leonor Freire Costa reconstruía las especies arbóreas empleadas en dichos astilleros a partir de fuentes tan diversas como las leyes de 1546 y 1579 , y algunos de los contratos firmados con el proveedor Diogo de Azevedo en la primera mitad 
del siglo XVI (Costa, 1997, pp. 305-223), mientras que Cristina Joanaz de Melo ha analizado más recientemente la transformación experimentada por los bosques reales portugueses en el tránsito del Antiguo Régimen al Estado nación (Melo 2001 y 2015). En cualquier caso, a finales del XVIII la extensión de estas áreas forestales es muy similar a la reconstruida para los siglos XVI y XVII por Felix Labrador Arroyo o por Koldo Trápaga Monchet y García-Rodríguez mediante el empleo de SIG [Sistema de Información Geográfica] (Melo, 2015, pp. 29-30; Labrador Arroyo, 2009, pp. 225-242; Trápaga Monchet y García Rodríguez, 2017).

Sin embargo, esta investigación presenta tres grandes diferencias frente a los trabajos que hemos citados. Primero, porque hemos consultado las fuentes conservadas en el Arquivo Histórico Ultramarino y en la Biblioteca y Arquivo do Ministerio de Obras Púbricas portugués, en las cuales se especifican los espacios de extracción de los árboles, yendo, por tanto, más allá de lo contenido al respecto en la legislación de la época. Segundo, porque trata de aportar luz acerca de quiénes fueron los agentes de la corona encargados de hacer llegar la madera a Lisboa. Y tercero, por centrar el grueso de la investigación en los primeros decenios del siglo XVII, una cronología que difiere de la considerada por los trabajos de Leonor Costa y Joanaz de Melo.

La documentación consultada revela que desde finales de la década de 1600 la corona recurrió a través del Conselho da Fazenda a comisiones «extraordinarias» para garantizar la provisión de maderas para construcción naval, el corte y la transformación y/o transporte de las mismas para la construcción naval. Algo que se hacía casi siempre bajo el sistema de administración directa y, muy probablemente, confiando el trabajo a individuos que pertenecían a la casa real de Portugal ${ }^{36}$. Estos agentes solían ser comisionados como feitores, paradójicamente, asumiendo las competencias de aquellos que hasta entonces habían ejercido ese oficio con anterioridad, tal y como se advierte a través de las quejas de Francisco de Andrade Araujo, quien en 1635 solicitaba ser «feitor das madeiras que se fabricão e embarcão no porto da vila de Pederneira», argumentando que su padre, abuelo y bisabuelo lo habían ejercido en el pasado a satisfacción de las autoridades ${ }^{37}$. De hecho, a la muerte de su padre, el soberano había otorgado el servicio del oficio, que no la propiedad, a Luis Borges y Duarte de Araujo, su tío, hasta que el mencionado Francisco de Andrade alcanzase la mayoría de edad. Sin embargo, Duarte de Araujo no ejercía este desempeño, ya que el Conselho da Fazenda estaba comisionando para el mismo a personas a las que se pagaban 500 reis diarios. De ahí que en los últimos años de su mocedad esta comisión extraordinaria fuese desempeñada por Manuel Gomes Pereira y otras personas, siempre «pelas mesmas comissioes». Ahora,

\footnotetext{
36 Por comisiones extraordinarias nos referimos a nombramientos ad hoc de ministros reales para una tarea concreta, cuando ya había ministros que tenían una plaza ordinaria para desempeñar esta tarea.

37 AHU, CU, Reino, 8/67. Siguientes líneas se fundamentan en Ibídem.
} 
en 1635, ya adulto, Francisco de Andrade pedía para sí el cargo, por lo que la corona envió al doctor Cristóvão de Silveira a Leiria y Pederneira para recabar información sobre su persona. Conforme a las declaraciones de testigos, Francisco de Andrade reunía todas las condiciones y aptitudes de capacidad, experiencia y patrimonio económico para su desempeño, si bien era acusado de ser cristiano nuevo, razón por la cual no se le otorgó el oficio. En consecuencia, el Conselho da Fazenda siguió apostando por las comisiones extraordinarias en lugar de acudir a los oficios «tradicionales» que hasta entonces se encargaban de la fábrica y transporte de las maderas ${ }^{38}$.

No se trataba este del único oficio dedicado a la gestión forestal que se perpetuaba o transmitía en el seno de una misma familia. Estaba también el de monteiro-mor (Labrador Arroyo, 2009, pp. 237-238; Trápaga Monchet, 2017, pp. 6-7). Un buen ejemplo de ello lo tenemos en la persona de Diogo Bayao de Resende, quien en 1638 solicitaba el oficio que João de Bayao de Resende, su padre, había desempeñado durante más de cincuenta años. João de Bayao había sido cavaleiro fidalgo de la casa real de Portugal y escribano del «recibimento e embarcação de suas madeiras no Porto da Pederneira», cometido por el cual había tenido un salario anual de 30.000 reis, lo que significaba que trabajaba unos 5 meses al año en el transporte de las maderas ${ }^{39}$ (Labrador Arroyo, 2009, p. 129). El guarda-mor del pinar de Leiria respaldaba la petición, porque, decía, el cargo requería del conocimiento de la calidad de las mencionadas maderas, de las «marquas» e implicaba un gran trabajo ${ }^{40}$.

En ocasiones, estos oficiales ordinarios, o tradicionales, encargados de la gestión de los recursos forestales eran seleccionados para la tala, transformación y/o conducción del maderamen a Lisboa. En 1608, el guarda-mor de Leiria, Jorge da Costa da Silva, obtuvo el contrato para esta provisión de maderas tras haber presentado una oferta a la baja, si bien, al año siguiente, el Conselho da Fazenda obtuvo de él una reducción de costos aún mayor ${ }^{41}$ (Trápaga Monchet, 2018). Mientras prevaleció la firma de contratos con el Conselho da Fazenda para el proceso de tala, corte, transformación y transporte, en ocasiones, la corona adjudicaba a un solo individuo cada una de sus distintas partes. Lo vemos en 1617, en el caso del mencionado Jorge da Costa, guarda-mor del pinar real de Leiria, a quien le fue ordenado acudir con Gaspar Bastolei a la villa de Pederneira, y acercarse a los bosques de Alcobaça para desde allí transportar las maderas que se iban a mandar a Lisboa ${ }^{42}$. Igualmente, a finales de

\footnotetext{
38 En 1637, el oficio fue requerido por Simão Alvares tras haber contraído matrimonio con María de Andrade, hija de Francisco de Araujo, AHU, CU, Reino, 9/3.

39 Resulta probable que estuviese emparentado con André Bayao, caballero fidalgo de la casa real que en 1587 fue nombrado, en interinidad, ejecutor del almojarifazgo de Leiria.

40 AHU, CU, Reino, 9/37.

41 AGS, SSP, lib. 1466, ff. 246r-249r y 1472, ff. 243v-244r.

42 AHU, CU, Reino, 2/25.
} 
1623, el mismo Jorge da Costa recibía el cometido de cortar entre 3.000 y 4.000 árboles de pinheiro-manso y pinheiro-bravo, cuya madera se había comenzado a labrar y aserrar el 22 de enero de 1624. Para ello, había recibido una cantidad de 600.000 reis, aunque él solicitó otros 800.000 para así cubrir los costes de su envío a Lisboa ${ }^{43}$. En mayo de 1624, los gobernadores del reino optarían nuevamente, tras una consulta previa al Conselho da Fazenda, por el guarda mayor de Leiria y sus oficiales para el traslado de las maderas cortadas en Leiria y Pederneira ${ }^{44}$.

No obstante, todo indica que en estas fechas la corona prefería recurrir mayoritariamente para estos encargos a las comisiones extraordinarias bajo la supervisión del Conselho da Fazenda. En las páginas que siguen, detallaremos algunas de las comisiones extraordinarias empleadas por la corona entre 1609 y 1640 , a la vez que damos cuenta de todas aquellas de las que tenemos noticia en la tabla infra (Tabla 1). El procedimiento que seguiremos a continuación será el de explicar el desarrollo y sentido adoptado por estas comisiones, para luego, en un segundo momento, procurar extraer los rasgos básicos de su funcionamiento. Lo haremos así, porque las fuentes no nos informan de la labor completa llevada a cabo por los comisionados extraordinarios, de ahí que tengamos que recomponerla por esta vía.

En la tabla hemos incluido al agente, su cometido, su lugar de actuación, la fecha en qué fue enviado o estuvo empleado, y la especie arbórea de la que debía proveer a los astilleros lisboetas. Desafortunadamente, disponemos de pocos detalles que nos permitan aportar más luz sobre estos comisionados. Aunque sí podemos decir, que la primera de las comisiones extraordinarias de la que tenemos noticia es la de Alfonso Alvares, quien en 1609 sería designado mestre de las maderas cortadas en el área de Santarém (Mapa 3), donde talaron 4.577 alcornoques, seleccionados conforme a la relación que en su momento le había entregado el proveedor dos armazéns, Vasco Fernándes Cesar, pensando en la confección de más de 6.000 componentes navales para una nao que navegaría hasta la India. Los cortes fueron realizados en las tierras de Agostinho de Rebelho, situadas en Charneca, en el término de Santarém ${ }^{45}$.

En 1619, el licenciado Manuel do Amaral fue escogido, junto al escribano de los pinares de Leiria, Luis da Costa, para supervisar los procesos de labrado, serrado y transporte del maderamen para el rey ${ }^{46}$. En 1621, Manuel Esteves Serrão era el feitor das madeiras en Leiria, contaba para ello con la colaboración de Jorge da Silva, guarda mayor del pinar de Leiria, y ambos tenían la obligación de realizar parte de los

AHU, CU, Reino, $4 \mathrm{a} / 10$

AHU, CU, Reino, 4a/27.

AHU, CU, Reino, 1/64.

AHU, CU, Reino, $3 / 26$. 
Tabla 1. Comisiones extraordinarias para la provisión de maderas, 1609-1639

\begin{tabular}{|c|c|c|c|c|}
\hline Agente & Año & Cargo/cometido & Área geográfica & Especie arbórea \\
\hline Alfonso Alvares & 1609 & Mestre de las maderas & Santarém & Alcornoque \\
\hline $\begin{array}{l}\text { Licenciado Manuel de } \\
\text { Amaral }\end{array}$ & 1619 y 1620 & $\begin{array}{l}\text { Labrar, serrar y transportar las } \\
\text { maderas }\end{array}$ & Leiria & Pino \\
\hline Manuel Esteves Serrão & 1621 & Feitor del corte de las maderas & Leiria & Pino \\
\hline Manuel Esteves Serrão & 1622 & Transporte & Leiria & Pino \\
\hline Gaspar do Basto Teixeira & 1622 & & $\begin{array}{l}\text { Escaroupim (Salvaterra } \\
\text { de Magos) }\end{array}$ & \\
\hline Licenciado Gaspar Cardoso & $\begin{array}{l}\text { Diciembre } 1622 \\
\text { - agosto } 1623\end{array}$ & $\begin{array}{l}\text { Corte, labrar y transporte de las } \\
\text { maderas }\end{array}$ & Leiria & Pino \\
\hline $\begin{array}{l}\text { Licenciado Valentim da } \\
\text { Costa }\end{array}$ & $\begin{array}{l}\text { Diciembre } 1622 \\
\text { - agosto } 1623\end{array}$ & Corte, fabricación y transporte & Santarém & Alcornoque \\
\hline $\begin{array}{l}\text { Pêro Vieira, en sustitución } \\
\text { del antecedente }\end{array}$ & Agosto 1623 & Traslado & Santarém & Alcornoque \\
\hline $\begin{array}{l}\text { João Monteiro, mozo de } \\
\text { câmara del rey }\end{array}$ & $\begin{array}{l}\text { Diciembre 1623- } \\
\text { enero } 1624\end{array}$ & Corte & Santarém & Alcornoque \\
\hline Licenciado Gaspar Cardoso & Febrero 1624 & & Leiria & Pino \\
\hline Agostinho Dias & Enero 1626 & Fábrica maderas & Melides (Alcácer do Sal) & Pino \\
\hline Pêro Vieira & Mayo 1626 & Feitor de las maderas & Mugé & \\
\hline Francisco Petana de Brito & Hasta mayo 1626 & Transporte & Mugé & \\
\hline Doctor Jerónimo de Souto & Mayo 1626 & Transporte & Mugé & \\
\hline Francisco Coutinho & Diciembre 1626 & Maestre de las maderas & Erra (Santarém) & Alcornoque \\
\hline Miguel Nunes & 1633 & Feitor & Santarém & Alcornoque \\
\hline Diogo Borges Bandeira & Septiembre 1634 & Feitor & Coruche & Alcornoque \\
\hline Diogo Borges Bandeira & 1635 & Feitor & & Alcornoque \\
\hline Agostinho Dias & \begin{tabular}{|l|} 
Abril-septiembre \\
1635
\end{tabular} & Transporte & Cabeção & Pinheiro-manso \\
\hline \multirow[t]{2}{*}{$\begin{array}{l}\text { Manuel Cardoso, juez de } \\
\text { crimen de Lisboa }\end{array}$} & Junio 1635 & Conducción maderas & Ribatejo & \\
\hline & Diciembre 1635 & & Ribatejo & \\
\hline Manuel Gomes Pereira & $\begin{array}{l}\text { Diciembre } 1635 \\
\text { - julio } 1636\end{array}$ & $\begin{array}{l}\text { Feitor para corte, transporte, } \\
\text { transformación }\end{array}$ & Leiria & $\begin{array}{l}\text { Pinheiro-mansoy } \\
\text { pinheiro-bravo }\end{array}$ \\
\hline Agostinho Dias & $\begin{array}{l}\text { Enero- } \\
\text { noviembre } 1636\end{array}$ & Corte, transporte, transformación & Óbidos & Pino \\
\hline Agostinho Dias & Diciembre 1636 & Feitor para corte & & Alcornoque \\
\hline João da Fonseca Coutinho & Diciembre 1636 & $\begin{array}{l}\text { Feitor para corte, transformación y } \\
\text { transporte }\end{array}$ & Ribatejo & Alcornoque \\
\hline Francisco Coutinho & Octubre 1637 & Feitor & Santarém & Alcornoque \\
\hline Manuel Gomes Pereira & Marzo 1638 & Feitor & Leiria & Pino \\
\hline Francisco Coutinho & Diciembre 1638 & Feitor & & Alcornoque \\
\hline Manuel Gomes Pereira & Enero 1639 & Feitor & Leiria & Pino \\
\hline $\begin{array}{l}\text { Manoel de Nobrega Vilas } \\
\text { Boas }\end{array}$ & $\begin{array}{l}\text { Mayo-agosto } \\
1639\end{array}$ & Feitor, conductor de maderas & Ribatejo & Alcornoque \\
\hline
\end{tabular}

FuENTE: Además de las citadas en las notas a pie de página de este apartado, véase AHU, CU, Reino, 3/75, 10/1, 9 y 41 (comisiones del licenciado Gaspar de Cardoso de 1622, y las tres últimas de esta tabla). 


\section{Mapa 2. Áreas de provisión de madera para los astilleros de Lisboa}

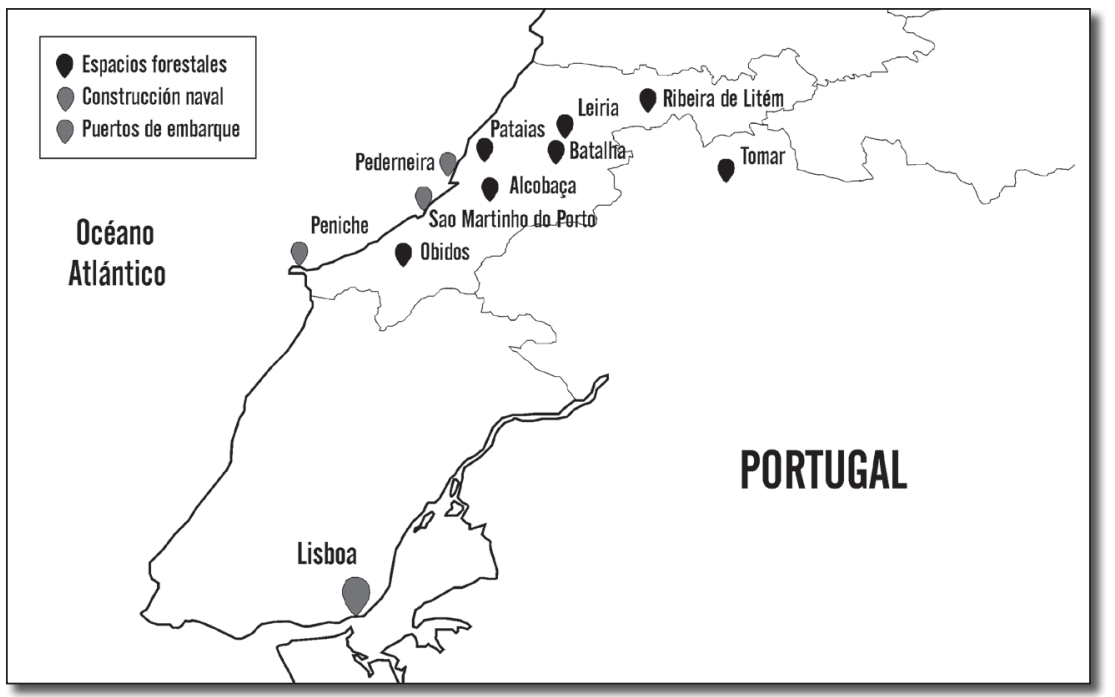

cortes en presencia del juez de Pederneira ${ }^{47}$ (Mapa 2). Al año siguiente, el mencionado Manuel, estaría nuevamente encargado del transporte de las maderas ${ }^{48}$.

En diciembre de 1622, el licenciado Gaspar Cardoso sería elegido por los gobernadores del reino para el corte en Leiria del maderamen necesario para la construcción de las dos naos nuevas que en 1624 zarparían a la India y la reparación de la que cabría hacer de la Armada de Portugal - la Armada del Consulado-. Aunque la mayoría de las comisiones se adjudicaban en noviembre o diciembre, ya que los árboles eran cortados durante las lunas menguantes de diciembre o enero, Gaspar Cardoso proponía esperar hasta el 20 de enero de 1623, en que había también la luna menguante ${ }^{49}$. Pocas semanas después indicaba que concluiría la tala el 28 de enero. Ya en febrero, demandaba el envío de 1.332.500 reis para terminar de «serrar» lo cortado. Las maderas solían ser transformadas en los lugares cercanos a la tala. Luego, desde allí, se trasladaban en carros de bueyes [carretos] o a través de las vías fluviales hasta Pederneira, donde carabelas u otras embarcaciones las conducían hasta Lisboa. La fabricación de las mencionadas maderas continuó a finales del mes de abril, si bien una parte de las mismas ya se encontraba apilada en Pederneira para su transporte a la capital del reino, algo para lo que hacían falta embarcaciones y dinero. El Conselho da Fazenda

AHU, CU, Reino, $3 / 46$.

AHU, CU, Reino, $3 / 55$.

AHU, CU, Consultas, cod. 35, ff. 6r-7r. 
dispuso entonces que el doctor Domingo Correa Campelho Pereira proporcionase a Gaspar Cardoso el numerario requerido. Sin embargo, en agosto todavía se le adeudaba dinero por el acarreo y saca del maderamen, de ahí que para acelerar el asunto el Conselho aprobase embargar carabelas para su traslado de Pederneira a Lisboa ${ }^{50}$.

A finales de 1622, el licenciado Valentim da Costa, juez del crimen, fue a su vez enviado a Santarém para el corte, fabricación y transporte de maderas de alcornoque. Valentim calculaba tener rematada la tala a finales de la luna de enero de 1623. Se cortaron 4.000 paos de alcornoque con destino a la construcción de dos naos y 360 árboles más para la fabricación de galeras. En abril ya se habían «fraguado», aserrado y mandado algunos de los pãos a Lisboa. Pocos meses después, nuestro licenciado rebajó la cantidad de árboles elaborados a 3.000 «e tantos paõs», un trabajo, decía, por el que se le adeudaban 900.000 reis. Por esta razón, Valentim se trasladó a Lisboa, donde indicó a los responsables del Conselho de Fazenda que no le sería posible enviar todas las maderas a Lisboa hasta septiembre. En el supuesto de que el mencionado Valentim no quisiese volver a trasladarse a los bosques de Santarem, los hombres del Conselho consideraban «muy necessario mandarsse um criado de Vossa Magestade de muita confiança como se mandaua por este Conselho para que não fiquem as madeiras no mato». Fue así que en agosto Pêro Vieira, sustituyendo a Valentim da Costa, remitía a las autoridades un presupuesto de lo que iba a costar el traslado de las restantes maderas de alcornoque, en él, se advertía se le adeudaban más de un 1.000 .000 de reis, el dinero dado a los barqueros por los fletes de maderas hasta Pederneira y el sueldo de los dos oficiales comisionados, es decir, el de Pêro Vieira y el del escribano asignado. En noviembre todavía seguía ocupado en el desempeño de la tarea asignada, por lo que sus trabajos se solaparon con los del inicio de la campaña de corte siguiente, en la luna de diciembre. Además, Agostinho Dias, se hallaba operando en el área del Ribatejo como encargado del corte, fabricación y transporte de las maderas de pinheiro-manso necesarias para la construcción de las dos naos nuevas, por lo que este año hubo en la zona hasta tres comisionados trabajando a un tiempo ${ }^{51}$.

En noviembre de 1623, al objeto de disponer de las talas necesarias, el Conselho da Fazenda solicitaba información sobre si las naos que iban a partir hacia la India en 1625 tendrían tres o cuatro cubiertas. Se dispuso luego que el constructor de las mismas, Valentim Themudo, entregase la relación de las maderas necesarias para ellas, planificándose su corte para las lunas de diciembre y enero ${ }^{52}$. Poco después, João Monteiro, mozo de cámara del rey, fue comisionado para el corte de maderas

Ibídem, ff. 37v-38r; ff. 51v-52r, 81r.; ff. 87v-88v.; ff. 149r-150v.

Acerca de todo ello, AHU, CU, Consultas, cod. 35, veáse ff. 37v-38r.; f. 83r-v; ff. 161r-162v.; ff. 87v-88v.; ff. 161r-162v. ff. 207v-208r.; f. 81r.

$52 \quad$ Ibidem, f. 213 r. 
Mapa 3. Zonas relacionadas con la provisión de madera para Lisboa (1609-1640)

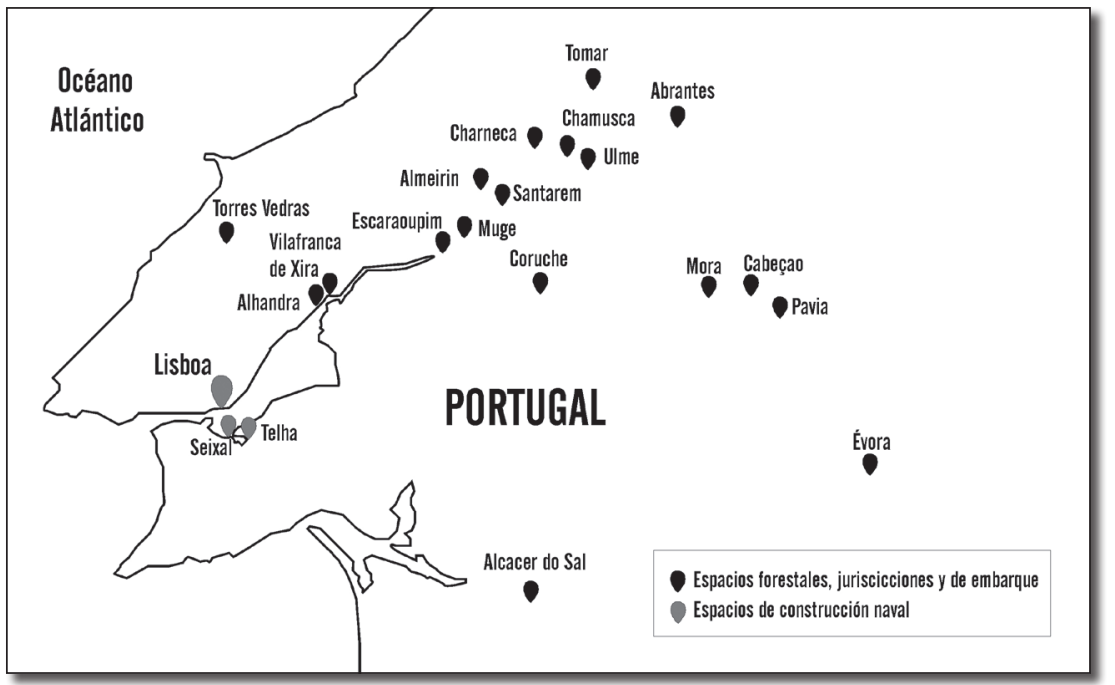

de alcornoque, que habría de realizarse en el término de Santarém durante la luna de enero. En este caso, se talaron unos 5.200 alcornoques para la construcción de dos naos nuevas de tres cubiertas, y otros 850 para posibles reparaciones. En sus labores, João Monteiro estuvo asistido por varios maestros remitidos a la zona por el gobierno lisboeta ${ }^{53}$. Así, entre enero y mayo de 1624 participaron en ellas hasta 80 frageiros bajo la dirección del mencionado João Monteiro, actuando como pagador el licenciado Luis de Goes $^{54}$. En la misma línea, solo que a finales de 1623, el ya citado licenciado Gaspar Cardoso sería comisionado para investigar el proceder de los feitores das madeiras del área de Leiria. Tras su investigación, a Cardoso se le encomendó el transporte de las maderas a Lisboa, lo que en este caso nos permite advertir la forma en la que el Conselho da Fazenda encargaba las tareas de inspección y cuidado de los bosques reales a los comisionados ${ }^{55}$.

El 25 de enero de 1626 Agostinho Dias llegó a Melides, en Alcácer do Sal, para la fabrica de las maderas de pino para las naos que en 1627 saldrían con destino a la India ${ }^{56}$. En mayo de ese año, Jerónimo de Souto sustituiría a Francisco Pestana de Brito en el transporte de la misma desde Muge, siendo Pêro Vieira el feitor das madei-

AHU, CU, Reino, 4a/10.

AHU, CU, Reino, 4a/29.

AHU, CU, Reino, 4a/12.

AHU, CU, Reino, 5a/4. 
$\operatorname{ras}^{57}$. Los carreteros se quejaron en mayo y junio de que aún no se les había pagado el acarreo realizado.

En diciembre de 1626, el soberano ordenó al monteiro-mor permitir el corte de alcornoques en los bosques de Santarém, siguiendo para ello la relación dada por el proveedor dos armazéns para la construcción de los galeones en Seixal. El monteiromor envió a Francisco Coutinho, maestre de las maderas del rey, para proceder a su tala en «Herra» ¿¿Erra?], la cual tuvo lugar en las tierras pertenecientes al monasterio de San Francisco, lugar donde antaño ya se habían acometido talas parecidas ${ }^{58}$. A comienzos de 1627, había un feitor das madeiras en Pederneira, y podemos aventurar que éste oficio continuó existiendo en años posteriores ${ }^{59}$.

Tenemos que esperar a 1633 a que Miguel Nunes sea nombrado feitor das madeiras de alcornoque construidas en la villa de Santarém ${ }^{60}$. Como se ha apuntado, estos feitores informaban de los desmanes que se cometían contra los bosques del rey, siendo por tanto ejecutores de las prácticas de protección forestal de la monarquía. Así se entiende que en septiembre de 1634, Diogo Borges Bandeira, feitor das madeiras de alcornoque que se cortaron en Coruche y otras áreas próximas a Santarém, denunciase la quema de maderas destinadas a la Armada del Consulado. Por esta razón, solicitó la colaboración de los jueces locales, sin obtener de ellos una respuesta favorable, lo que le llevó a acudir al Conselho da Fazenda, el cual, ante la gravedad del hecho, propuso a tres juristas para que investigasen lo sucedido y castigasen severamente a los culpables de tales desmanes ${ }^{61}$. Al margen de esto, Diogo Borges se había obligado a situar en 1634 unos 5.500 paos de alcornoques en Lisboa, si bien tuvo problemas para realizar su cometido. En septiembre apenas había conseguido enviar 2.500 y todavía quedaba pendiente el transporte de los 3.000 restantes, que no podía hacer por adeudar a los carreteros 850.000 reis. Las dificultades de Diogo no terminaron ahí, ya que, sin dinero, fracasó luego a la hora de conseguir que los jueces de los povos de Vilafranca [¿Vila Franca de Xira?] y Alhandra obligasen a los barqueros a realizar el transporte del maderamen ${ }^{62}$.

Agostinho Dias sería elegido en abril de 1635 para ir a buscar maderas «de cabedos $\rangle^{63}$. Ese mismo mes, los jueces ordinarios de las villas de Cabeção, Pavia, Mora y Coruche y el ouvidor de la Casa de Aviz recibieron órdenes del Conselho da Fazenda

AHU, CU, Reino, 5a/17. Estas líneas se fundamentan en Ibídem.

AHU, CU, Reino, 5a/38.

AHU, CU, Reino, 38/33.

AHU, CU, Reino, 6/33.

AHU, CU, Reino, 6/35 y Consultas, cod. 504, f. 4r-v.

AHU, CU, Reino, 8/35.

AHU, CU, Reino, 7a/20. 
para entregarle a él, o a la persona que mandara, los carros y carretas necesarios para el transporte de 800 árboles de pinheiro-manso y 40 docenas de tablas de costado que se habían cortado en el pinar real de Cabeção, para de este modo conducirlas al afluente del río quince días antes de que se secase la ribeira, al objeto de trasladarlo todo de Coruche a Benavente ${ }^{64}$. En mayo, el mencionado Conselho dispuso las órdenes pertinentes para que los corregidores de las villas de Tomar y Évora proporcionasen los citados carros para el acarreo de las maderas ${ }^{65}$, las cuales fueron entregadas en septiembre al proveedor de la comarca de Torres Vedras ${ }^{66}$. En junio, el Conselho da Fazenda comisionaba a Manoel Cardoso, juez del crimen de Lisboa, para que fuese a Ribatejo y condujese a Lisboa el maderamen dispuesto para la construcción de las naos que deberían partir hacia la India. Para hacer más efectiva su misión, se le otorgó, además, potestad suficiente para actuar en todo el área del Ribatejo. Pocas semanas después, una potestad semejante se le dio al licenciado Jacinto Ribeiro, juez de la ciudad de Lisboa ${ }^{67}$. Pese a ello, en diciembre todavía no se habían trasladado a Lisboa las maderas cortadas a comienzos de año en Ribatejo y Pederneira, por lo que hubo que nombrar otro comisionado en este último emplazamiento que agilizase las operaciones de traslado ${ }^{68}$.

Pero la actividad forestal no se detenía, y en diciembre de 1635 las autoridades lisboetas disponían los cortes de maderas que se habían de realizar para la construcción de la nau nueva que en 1637 navegaría rumbo a la India. Los alcornoques se extraerían una vez más del Ribatejo y los pinos de la zona de Leiria. Para estas tareas fue comisionado Manuel Gomes Pereira y se preveía la asistencia personal del provedor dos armazéns, quien contaría con la ayuda del guarda mayor y del personal de Leiria para el corte, fabricación y transporte del maderamen. Además de ello, Manuel Gomes Pereira estaría asistido también por el juez de los coutos de Alcobaça, que gestionaría la paga del precio justo de las maderas - por lo que probablemente los cortes iban a realizarse en tierras de particulares - y contaría con la potestad de embargar las carabelas que estuviesen atracadas en los puertos de Pederneira, São Martinho y Peniche, para así garantizar el transporte los cortes a Lisboa ${ }^{69}$.

En enero de 1636, volvemos a encontrar nuevamente a Agostinho Dias operando en la comarca de Óbidos, donde ese año hubo al menos tres comisionados más. La tala encargada sería realizada de acuerdo con el provedor dos armazéns, contando con el

AHU, CU, Reino, 38/43.

AHU, CU, Reino, 7a/44.

AHU, CU, Reino, 8/33.

AHU, CU, Reino, 38/44 y Consultas, cod. 504, f. 46v.

AHU, CU, Reino, 8/63.

AHU, CU, Reino 8/66. 
apoyo del juez de la comarca y los demás oficiales reales de la zona ${ }^{70}$. Agostinho Dias tenía encargado también el corte de maderas de pino para la realización de tablado, el cual fue realizado en el pinar real de Cabeção, aunque, desafortunadamente, no había podido luego mandarlas por el cauce fluvial. No sería hasta noviembre de 1636 que no se lanzase el maderamen al agua, pero sin demasiado éxito a causa de las lluvias. Por ello, el comisionado solicitaba a las autoridades lisboetas mandato para poder colectar barcas al objeto de juntarlo y llevarlo hasta Benavente ${ }^{71}$.

En julio de 1636, el feitor Manuel Gomes concluía por su parte la fábrica y corte de pinheiros-manso y pinheiro-bravo en la zona de Leiria, todo ello con destino a la construcción de una nao nueva, el arreglo de otra y de dos galeones de la armada por la cantidad de 2,3 millones de reis. En sus informes, destacaba la altísima calidad de las maderas fabricadas, pero demandaba el cobro de lo que se le adeudaba para poder terminar el trabajo y transportar el maderamen hasta Lisboa. Un traslado que debía ser realizado antes de septiembre, ya que, probablemente, a partir de entonces las condiciones meteorológicas y las corrientes marítimas dificultarían las operaciones de traslado ${ }^{72}$.

En diciembre de 1636, el mencionado Agostinho Dias recibía el nuevo encargo de cortar alcornoques para finalizar los galeones que se estaban construyendo en Telha, lo que significa que estuvo trabajando al menos tres años como feitor das madeiras en la zona. En este caso, la tala fue realizada conforme a la relación que le dio el maestro constructor: 3.035 alcornoques, los cuales se cortarían en las tierras de Francisco Andrade Leitão y de doña Francisca de Mendoza, quienes se negaron ello, al menos hasta que no se les indicase el número exacto de árboles a talar en sus tierras y se les pagase por anticipado. El corte estaba previsto para el 12 de diciembre ${ }^{73}$, y también en diciembre fue, probablemente, comisionado João da Fonseca Coutinho como feitor para dicho corte y transporte del maderamen en Ribatejo. Entre finales de febrero y comienzos de marzo éste había remitido ya 2.207 pãos de alcornoque a Lisboa, si bien advertía que otros 200 se habían perdido en Escaroupim por la falta de colaboración del corregidor de Santarém y el juez de Vila-Franca.

La fiebre maderera originada por las necesidades navales no se detenía y en octubre de 1637, Francisco Coutinho, feitor en el área de Santarém solicitaba al Conselho da Fazenda que ordenase al juez de fora de Vila-Franca mandar el barco de Agostinho Roiz a Santarem, el cual, por sus grandes dimensiones, permitía sacar de la zona maderas más grandes. Asimismo, indicaba que debían darse órdenes en el mismo sentido a los dueños de otras embarcaciones ${ }^{74}$. En marzo de 1638, el citado Manoel Gomes

\footnotetext{
AHU, CU, Reino, 8a/4.

AHU, CU, Reino, 8a/43.

AHU, CU, Reino, 8a/13.

Ibídem.

AHU, CU, Reino, 9/4.
} 
Pereira pedía a su vez al citado Conselho, en su calidad de feitor das madeiras do rei de la comarca de Leiria, la remisión del dinero procedente de la villa de Tomar para fabricar y transportar el maderamen ${ }^{75}$. Para ese transporte, el proveedor dos armazéns, Vasco Fernandes Cesar, involucraría al ouvidor dos coutos de Alcobaça, a los jueces ordinarios de la villa de Pederneira y a los demás justicias de la misma ${ }^{76}$. Todo debía de estar listo para marzo, y ser transportado en abril y mayo ${ }^{77}$.

Del análisis de los casos expuestos, podemos extraer algunas conclusiones. Primero, que la corona recurrió, en mayor medida, a los comisionados extraordinarios bajo el control del Conselho da Fazenda (Tabla 1). La mayoría de las veces, estos comisionados reemplazaban a los ministros ordinarios que habitualmente habían desempeñado las funciones de corta, transformación y transporte de madera. En ocasiones, y resulta probable que esta fuese la fórmula más habitual, el mencionado Conselho nombraba a un comisionado extraordinario bajo cuya dirección trabajaban luego los ministros ordinarios — como por ejemplo el guarda-mor del pinar de Leiria, el escribano de los pinares y fábrica de las maderas del rey en Leiria o el escribano del «recibimento e embarcação de suas madeiras no Porto da Pederneira»—. Estos comisionados reunían además la condición de ser funcionarios reales con formación jurídica, letrados por tanto, y ser criados de Su Majestad, al tener un oficio en el seno de la casa real de Portugal. En la década de 1630 vemos que la corona todavía recurría a estos mismos oficiales para los mismos asuntos. Este fue sin duda el caso, por ejemplo, de los mencionados Agostinho Dias y Manuel Gomes Pereira.

Segundo, en cuanto a la búsqueda de nuevas áreas de extracción de maderas, la corona solía desplegar anualmente dos comisionados extraordinarios. El primero de ellos, trabajaba en la zona de Leiria-Óbidos-Alcobaça, cuyo maderamen era posteriormente trasladado a Pederneira o Peniche, desde donde se embarcaba en carabelas cara a Lisboa (Mapa 2). Un espacio geográfico que coincide con el indicado en su día por Leonor Costa (Costa, 1997, pp. 319-322). El segundo comisionado solía estar más centrado en el área situada entre Lisboa y Abrantes, a ambas orillas del río Tajo (Mapa 3). De aquí se extraían sobre todo alcornoques y los componentes navales fabricados a partir de ellos, si bien también hay algunas referencias a la saca de pinheiros-mansos y pinheiros-bravos. Entrecruzando la información archivística con los mapas geográficos obtenidos mediante el SIG, puede aventurarse que con el paso de los años los comisionados de la corona tuvieron tuvieron que irse alejando de las

\footnotetext{
75 AHU, CU, Reino, 8/40. Las maderas se habían cortado durante las lunas de diciembre y enero en pinares del rey y de particulares para la construcción de una nao nueva que debía navegar a la India, AHU, CU, Reino, caixa, 38/50.

76 AHU, CU, Reino, 9/42.

77 AHU, CU, Reino, 38/50.
} 
áreas fluviales para de este modo encontrar maderas apropiadas de pino y alcornoque para la construcción de los distintos componentes navales; aspecto este que podría indicar la existencia de un relativo grado de deforestación, cuya magnitud sería un tema de debate del que no cabe ocuparse ahora.

Tercero, durante su cometido, los comisionados extraordinarios tuvieron que hacer frente a multitud de dificultades, como ajustar los cortes a un calendario preciso, ya que eran nombrados por la autoridades hacia finales de noviembre o comienzos de diciembre, para así proceder a la tala de las maderas en el curso de las lunas menguantes de diciembre o enero. Es decir, había un número concreto de días a los que forzosamente debían ajustar su trabajo, en caso contrario, la calidad de las maderas podría verse comprometida. Ese trabajo solía durar cinco meses, durante los cuales, probablemente, se empleaban en él a decenas de personas.

Cuarto, al mismo tiempo que se cortaban, labraban y transformaban las maderas en componentes navales, se enviaban algunas de ellas a Lisboa. Estos traslados se veían condicionados por elementos como la logística y los factores climáticos. El transporte fluvial hasta el Tajo, o bien desde la zona de Pederneira y Peniche, requería la movilización de decenas de pequeñas embarcaciones y de algunas carabelas, cuyos propietarios no siempre estaban dispuestos a colaborar con las autoridades reales. Por esta razón, los comisionados extraordinarios solían pedir al Conselho da Fazenda potestad para que las justicias locales y provinciales obligasen a los habitantes de la zona a poner a su disposición carros y bueyes - para conducir la madera por tierra hasta la inmediaciones de los ríos - o embarcaciones - para el transporte de la madera por los cauces fluviales - . Asimismo, demandaban que las carabelas que fuesen lo suficientemente grandes como para transportar piezas de mayor magnitud hasta los astilleros. En caso contrario, algunos componentes de los barcos que iban a construirse en ellos tenían que cortarse en unidades más pequeñas, con el consiguiente costo económico de ensamblar las piezas, de incrementar las posibilidades de que el agua se filtrase en ellas con mayor facilidad y de poner en riesgo la fabricación o reparación de las embarcaciones del monarca. Por lo demás, la conducción de la madera por las vías fluviales hasta los puertos de embarque - Pederneira o Peniche — o de construcción naval Lisboa- debía realizarse en unas fechas muy concretas, ya que, como se ha dicho, las crecidas de los ríos o la falta de agua dificultaban sobremanera todo este proceso.

Y quinto, las dificultades financieras fueron siempre un problema endémico, pues retrasaban el corte, la transformación y el transporte del maderamen. En ocasiones, con resultados muy negativos, al quedar este apilado en los bosques o en los puertos de embarque como Peniche o Pederneira, con riesgo de padecer por ello un importante y definitivo deterioro. De lo que no hay duda es que la obtención y elaboración de la madera era un proceso muy complejo, en el que, en más de una ocasión, los trabajos 
de una campaña se solapaban con las del año siguiente, tal y como vimos en el caso de Pêro Vieira anteriormente expuesto.

\section{Conclusiones}

La corona portuguesa comenzó a emitir su legislación forestal a mediados del siglo XIV, intensificándose el número y complejidad de las disposiciones a finales del siglo XV y comienzos del XVI. En un principio, esa legislación se fundamentaba en la necesidad de disponer de masas forestales suficientes para las actividades cinegéticas, si bien con la fijación de la corte en Lisboa y el inicio de la época de los Descubrimientos, toda ella comenzó a tomar en consideración la preservación de masas arbóreas para la construcción naval. Una «razón de ser» que sería consolidada toda vez que Felipe II se convirtió en rey de Portugal. Así, las medidas al respecto adoptadas durante las décadas de 1590 y 1600 contemplaban la posibilidad legal de incorporar y/o gestionar los bosques de los particulares en beneficio de la administración real. Aunque es posible también que se tratase de una práctica anterior, los datos aportados en este trabajo muestran cómo ésta fue aplicada a lo largo de los años que van de 1600 a 1640.

En el curso de dicho trabajo hemos visto asimismo varios casos de creación y/o aumento de los bosques reales por medio de la figura de coutar: este sería el caso del pinar de Leiria, del de Cabeção, los «chãos» de Almeirim o del pinar de Medos. Para ello, la corona recababa, en primer lugar, información mediante la figura de un comisionado o de uno o varios ministros que, posteriormente, enviaban informes a los tribunales administrativos asentados en Lisboa, en particular al Conselho de Fazenda. En ellos, detallaban de una forma más o menos pormenorizada la extensión territorial, los árboles disponibles y su estado, los dueños de los mismos y un cálculo aproximado del dinero que habría que desembolsar para coutar el territorio. Igualmente, prestaban especial atención a la calidad de las masas forestales para construcción naval y a la distancia de los árboles con respecto a las áreas fluviales y a los puertos desde los que se transportarían las maderas hasta los astilleros, sitos sobre todo en las inmediaciones de la mencionada cuidad de Lisboa. Partiendo de esos informes los tribunales administrativos —en el caso aquí estudiado, el citado Conselho da Fazenda - ponderaban la conveniencia de incorporar o no esos territorios. En caso afirmativo, debía enunciarse con claridad que la integración de las tierras al patrimonio real era para la construcción naval, lo que redundaría en el «bien de los vasallos». Entonces, el ministro procedía — tal y como hizo Jorge de Araujo Estacos en el pinar de Cabeção - a su incorporación y al establecimiento de unas prácticas y un sistema de conservación del bosque, así como de funcionamiento del personal administrativo encargado de vigilarlo y explotarlo. 
La corona procedió asimismo de forma activa en el reconocimiento de nuevos espacios geográficos que tuviesen las pertinentes masas forestales. La casuística de la exploración de la zona comprendida entre Santiago de Caçem y el reino de Algarve realizada en la década de 1610 denota el creciente interés de las autoridades por ampliar las tradicionales áreas de provisión de madera al sur del Tajo. Los informes emitidos por los oficiales reales durante las décadas de 1610 a 1630 sugieren en este sentido un incremento de los lugares destinados a proveer de maderamen de pino y alcornoque para las armadas reales en esas zonas. Se ha demostrado que la corona empleó tanto el sistema de asiento como el de la administración directa para satisfacer las necesidades madereras de Lisboa. Sin embargo, la modalidad que más se repitió en esos años fue el de la administración directa - a través del Conselho da Fazen$d a$-, consistente en el nombramiento de los ya citados comisionados extraordinarios y personal bajo su dirección.

Para finalizar, resulta complicado valorar el alcance que tuvieron estas comisiones en la política forestal puesta en práctica por la Monarquía Católica en relación a la construcción de sus armadas. James Bojayian ha señalado que desde la década de 1600 el número de barcos llegados a Lisboa desde la India fue descendiendo paulatinamente, para alcanzar su nivel más bajo en la década de 1630-1639 y, más concretamente, en los años finales del decenio (Bojayian, 1993, pp. 202-209). Por el contrario, del estudio de Amândio Barros se deduce que el quinquenio de 1631-1635 habría sido el de mayor actividad conocida en la construcción de galeones de gran porte para las mencionadas armadas reales en la ciudad de Oporto (Bârros, 2015, p. 199). Frente a esto, de nuestro estudio acerca de lo sucedido en la ciudad de Lisboa, se desprende la disminución de la construcción naval en sus astilleros; una disminución que, pese a todo, no parece haber sido lo suficiente grande como para explicar esa caída tan significativa de la llegada de navíos procedentes de la India. Lo que sí se ha demostrado en cambio en este trabajo, es que la corona solventó con razonable éxito la provisión de maderas para la construcción naval lisboeta, aunque, probablemente a un nivel inferior a las necesidades que generaban los conflictos mantenidos con los holandeses y otras potencias europeas en Brasil y Asia.

\section{AGRADECIMIENTOS}

Este trabajo se inscribe dentro de la actuación del proyecto La herencia de los reales sitios. Madrid, de corte a capital (Historia, Patrimonio y Turismo) (H2015/HUM3415) de la Convocatoria de Programas de I+D en Ciencias Sociales y Humanidades 2015 de la Comunidad de Madrid, financiado con el FSE. 


\section{Bibliografía}

Albion, Robert G. (1926), Forests and sea power. The timber problem of the royal Navy 1652-1862, Cambridge, Harvard University Press.

Andrade E SiLva, José J. de (1854), Collecção chronologica Legislação portuguesa compilada e anotada, Lisboa, Imprensa de J. J. A. Silva, vol. III.

Arala Pinto, António (1938), O Pinhal do Rei - Subsídios, Alcobaça, Oficina de J. de Oliveira Junior, 2 vols.

AppuHn, Karl (2000), «Forests, Forestry, and State Power in Renaissance Venice», The Journal of Modern History, 72/4, pp. 861-889. https://doi.org/10.1086/318548

Bamford, Paul W. (1956), Forests and French Sea Power 1660-1789, Toronto, Toronto University Press. https://doi.org/10.3138/9781442656550

Barros, Amândio (2015), Porto. A construção de um espaço maritimo no início dos tempos modernos, Lisboa, Academia de Marinha.

Bluteau, Rafael (1799), Diccionario da Lingua Portugueza, Lisboa, Officina de Simão Thaddeo Ferreira, vol. 1.

BoyaJian, James C. (1993), Portuguese Trade in Asia under the Habsburgs, 1580-1640, London, John Hopkins University Press.

Cabral, Diogo de y Cesco, Susana (2008), «Árvores do rei, floresta do povo: A instituição das 'madeiras-de-lei' no Rio de Janeiro e na ilha de Santa Catarina (Brasil) no final do período colonial», Luso-Brazilian Review, 44/2, pp. 50-86. https://doi.org/10.1353/lbr.2008.0007

Cortesão, Jaime (1993), Influencia dos Descobrimentos Portugueses na História da Civilização, Lisboa, Casa da Moeda.

Costa, Leonor (1997), Naus e galeões na ribeira da Lisboa. A costruçao naval no século XVI para a Rota do Cabo, Cascais, Patrimònia.

Crespo Solana, Ana (2013), «La Historia geográficamente integrada y los Sistemas de Información Geográfica (SIG): concepto y retos metodológicos», Tiempos Modernos, 26. http://www.tiemposmodernos.org/tm3/index.php/tm/article/ view/331/373

DADson, Trevor (1991), «Conflicting views of the Last Spanish Viceroy of Portugal (1617-1621): Diego de Silva y Mendoza, Count of Salinas and Marquis of Alenquer», Portuguese Studies, 7, pp. 29- 60.

DeVy-VARETA, Nicole (1985), «Para uma geografia histórica da floresta portuguesa. As matas medievais e a «Coutada velha» do Rei», Revista da Faculdade de Letras - Geografia, 1, pp. 47-67. 
DeVy-VARETA, Nicole (1986): «Para uma geografia histórica da floresta portuguesa. Do Declínio das matas medievais à política florestal do Renascimento (séc. XV e XVI)», Revista da Faculdade de Letras - Geografia, 1/1, pp. 5-37.

FALKOWSKI, Mateusz (2017), «Fear and abundance: reshaping or royal forests in sixteenth-century Poland and Lithuania», Environmental History, 22/4, pp. 618-642. https://doi.org/10.1093/envhis/emx055

GaIllard, Claude (1982), Le Portugal sous Philippe III d'Espagne. L'action de Diego de Silva y Mendoza, Grenoble, Université des Langués et Lettres de Grenoble.

Goodman, David (1997), Spanish Naval Power, 1589-1665: Reconstruction and Defeat, Cambridge, Cambridge University Press.

Hespanha, António Manuel (1989), «O Governo dos Áustria e a «modernização» da constituição política portuguesa», Penélope, 2, pp. 50-73.

Kamen, Henry (1998), Felipe de España, Barcelona, Siglo XXI.

Labrador Arroyo, Félix (2009), La Casa Real en Portugal (1580-1621), Madrid, Polifemo.

Labrador Arroyo, Félix (2018), voces «Jorge de Ataide» y «Pedro Castilho», en Diccionario Biográfico Español, vols. 6 y 12, pp. 22-24 y 405-406.

LANE, Frederic Chapin (1975), Venetian ships and shipbuilders of the Reinassance, Westport, Glenwood Press.

Magalhaes, Joaquim Romero (1970), Algarve económico durante o século XVI, Lisboa, Cosmos.

Martínez González, Alfredo José (2015a), Las Superintendencias de Montes y Plantios (1574-1748): derecho y política forestal para las armadas en la Edad Moderna, Valencia, Tirant Lo Blanc.

MArTínez GonzÁlez, Alfredo José (2015b), «Los asentistas de maderas, relaciones contractuales para las armadas hispánicas (siglos XVI-XVIII)», en Iglesias Rodríguez, Juan José et alii (eds.), Comercio y cultura en la Edad Moderna, Sevilla, EUS, pp. 1195-1214.

Mauro, Fredéric (1983): Le Portugal, Le Bresil et l'Atlantique au XVIIe siecle (1570-1670), París, Fondation Calouste Gulbenkian.

Melo, Cristina Joanaz de (2000), Coutadas Reais (1777-1824). Privilégio, Poder, Gestao e Conflito, Lisboa, Montepio Geral.

Melo, Cristina Joanaz de (2015), An Analysis of the Royal Preserves in Portugal. Issues of privilege, power, management and conflict, Wildtrack Publishing, Sheffield.

MurteIrA, Andre (2011), «O Estado da Índia e as companhias das Índias Orientais neerlandesa e inglesa no Índico Occidental, 1600-1635», en Martínez Hernández, Santiago (coord.): Governo, política e representações do poder no Portugal 
Habsburgo e nos seus territórios ultramarinos (1581-1640), Lisboa, CHAM, pp. 177-195.

MurteirA, Andre (2012), «El impacto de la tregua de los doce años en los dominios ultramarinos portugueses», en García García, Bernardo Jose et alii, El arte de la prudencia. La tregua de los doce años en la Europa de los pacificadores, Madrid, Fundación Carlos de Amberes, pp. 275-293.

Neves, Carlos Maria Baeta (1965), «Algunos documentos do Arquivo Nacional da Torre do Tombo sobre Monteiros-Mores, caçadores-mores e caçadores e couteiros de perdizes», Anais do Instituto Superior de Agronomia, separata del vol. 28.

OliveIRA, António de (1965), «Para a história do repovoamento florestal de Coimbra no século XVI», Arquivo Coimbrão, XXI-XXII, pp. 5-35.

OWENs, Jack B. (2007), «Toward a geographically-integrated, connected world history: employing geographic information systems (GIS)», History Compass, 5/6, pp. 2014-2040.

Perlin, John (2005), A Forest journey: The Story of Wood and Civilization, WoodstockVermont, Countryman Press.

RADKAU, Joachim (2008), Nature and power: a global history of the environment, Cambridge, Cambridge University Press.

Rahn Philips, Carla (1991), Seis galeones para el rey de España. La defensa imperial a principios del siglo XVII, Madrid, Alianza Editorial.

SÁNCHEZ TORRES, Rafael (2013), «Administración o asiento. La política estatal de suministros militares en la Monarquía española del siglo XVIII», Studia Histórica. Historia Moderna, 35, pp. 159-199. http://dx.doi.org/10.14201/shhmo201335159199

Thompson, Irving A.A. (1976), War and Government in Habsburg Spain (1650-1620), Londres, The Athlone Press.

TráPAga Monchet, Koldo (2017), «El estudio de los bosques reales de Portugal a través de la legislación forestal en las dinastías Avis, Habsburgo y Braganza (c. 1435-1650)», Philostrato, 1, pp. 5-27. https://doi.org/10.25293/philostrato.2017.01

Trápaga Monchet, Koldo (2018), «Traed madera”: agentes y vías de provisión de madera para las flotas reales en Portugal», en Pérez Samper, María Ángeles y Beltrán Moya, José Luis (eds.), Nuevas perspectivas de investigación en Historia Moderna, Madrid, FEHM, pp. 106-119.

Trápaga Monchet, Koldo, García Rodríguez, María José (2017), «Los aprovechamientos forestales de los bosques portugueses desde una perspectiva cartográfica durante la Unión Ibérica (c. 1580-1640)», en Rodríguez Ortega, Nuria (ed.), III Congreso de la Sociedad Internacional Humanidades Digitales Hispánicas. Sociedades, Políticas, Saberes, Málaga, pp. 73-78. 
VASCONCELlos, Frazão de (1928), «A fábrica das naus da carreira da Índia no século XVII», Anais do club Militar Naval, 9-10, s.p., 15 páginas.

WARDE, Paul (2006), «Fear of Wood shortage and the reality of the Woodland in Europe, c. 1450-1850», History Workshop Journal, 62, pp. 28-57. https://doi. org $/ 10.1093 / \mathrm{hwj} / \mathrm{dbl} 009$

Williams, Michael (2006), Deforesting the earth: from prehistory to global crisis: an abridgment, Chicago \& London, Chicago University Press. https://doi. org/10.7208/chicago/9780226899053.001.0001

WING, John T. (2012), «Keeping Spain afloat: State Forestry and Imperial Defense in the Sixteenth Century», Enviromental History, 17 (1), pp. 116-145. https://doi. org/10.1093/envhis/emr123

WING, John T. (2015), Roots of empire: State formation and the politics of timber Access in early modern Spain, 1556-1759, Leiden, Brill. 